\title{
Suistalinable

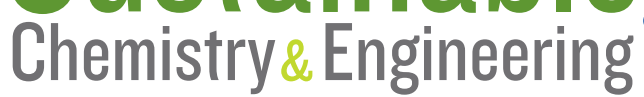 \\ Design and Synthesis of Bio-Based High-Performance Trioxazine Benzoxazine Resin via Natural Renewable Resources
}

\author{
Kan Zhang, ${ }^{* \dagger}{ }^{\dagger}$ Mengchao Han, ${ }^{\dagger}$ Yuqi Liu, ${ }^{\dagger}$ and Pablo Froimowicz ${ }^{*}+\vdots$ \\ ${ }^{\dagger}$ Research School of Polymeric Materials, School of Materials Science and Engineering, Jiangsu University, 301 Xuefu Road, \\ Zhenjiang, Jiangsu 212013, P.R. China \\ ${ }^{\ddagger}$ Design and Chemistry of Macromolecules Group, Institute of Technology in Polymers and Nanotechnology (ITPN), \\ UBA-CONICET, FIUBA, FADU, University of Buenos Aires, Intendente Güiraldes s/n, Pabellón III, subsuelo, Ciudad \\ Universitaria (C1428EGA), Buenos Aires C1428EGA, Argentina
}

ABSTRACT: A new fully biobased trioxazine benzoxazine is synthesized by reacting resveratrol, furfurylamine, and paraformaldehyde via the Mannich condensation reaction. The chemical structure of this biobenzoxazine is characterized by ${ }^{1} \mathrm{H}$ and ${ }^{13} \mathrm{C}$ nuclear magnetic resonance and Fourier transform infrared (FT-IR) spectroscopies. ${ }^{1} \mathrm{H}-{ }^{1} \mathrm{H}$ nuclear Overhauser effect spectroscopy is utilized to unambiguously identify the isomer obtained. Monomer polymerization is investigated by differential scanning calorimetry and in situ FT-IR. Thermal stability of the fully polymerized polybenzoxazine is evaluated by thermogravimetric analysis, and flammability is assessed by microscale combustion calorimetry. The biothermoset obtained shows high thermal stability and low flammability, $T_{\mathrm{d} 10}$ of $403{ }^{\circ} \mathrm{C}$ and char yield of $64 \%$, respectively, low heat release capacity $(54 \mathrm{~J} / \mathrm{gK})$, and low total heat release $(9.3 \mathrm{KJ} / \mathrm{g})$, thus exhibiting self-extinguishing and nonignitable properties. Consequently, this new fully biobased trioxazine benzoxazine and its corresponding polybenzoxazine possess excellent processability and thermal properties, suggesting great potential toward high-performance and fire-resistant materials.

KEYWORDS: Benzoxazine, Resveratrol, Natural renewable resources, High performance, Chemical design

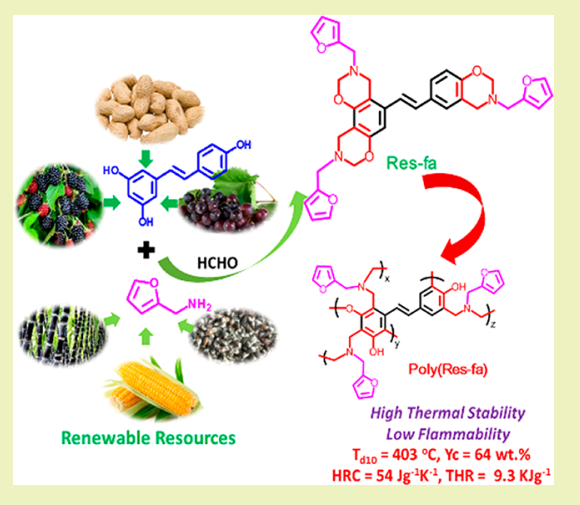

\section{INTRODUCTION}

Benzoxazine, as a class of relatively new thermosetting resin, can be readily prepared by using phenols, amines, and formaldehyde as starting raw materials carrying out the Mannich condensation reaction. ${ }^{1-4}$ The complex chemical structure of benzoxazines and the vast existence of rich phenolic and amino derivatives in nature allow researchers to obtain these resins with very high molecular design flexibility. This might be one of the main reasons why the field of benzoxazines has constantly been attracting attention from both academia and industry due to their attractive characteristics, including catalyst-free polymerization, ${ }^{5,6}$ high thermal stability, ${ }^{7,8}$ good mechanical properties, ${ }^{9,10}$ low dielectric constant, ${ }^{10,11}$ and low surface free energy. ${ }^{12-14}$ Intrinsic good compatibility with other traditional polymers is another beneficial feature of benzoxazines. Thus, benzoxazine resins are widely utilized to enhance specific properties of aimed materials by blending or copolymerization. ${ }^{15,16}$ All of the above-mentioned advantages make benzoxazine resins attractive candidates for high-performance applications.

As many other commercialized polymers, benzoxazine resins are facing the same challenges in terms of availability of raw materials from petrochemistry and the associated costs. The massive use of petroleum-based polymeric materials has led to potential toxic wastes, causing the subsequent environmental pollution. ${ }^{17}$ Therefore, exploring the use of chemicals from renewable resources to synthesize biobased polymers is necessary in order to meet the requirements for sustainable development. ${ }^{18-22}$ In the past decade, much effort has been paid toward the generation of biobased polymers capable of competing with petroleum-based materials. ${ }^{23,24}$ Anastas and Warner have provided guidance, summarizing the relevance of using renewable biobased raw materials. ${ }^{25}$ Recent efforts for developing biobased polymers by polymerizing fully or partially biobased benzoxazine resins have been synthesized by using alternative phenolic and amine compounds. Thus, cardanol, $^{26}$ urushiol, $^{27}$ vanillin, $^{28}$ guaiacol, $^{29}$ eugenol, $^{30}$ and coumarin $^{31,32}$ are examples of phenolic - $\mathrm{OH}$ sources, whereas stearylamine, $^{29}$ furfurylamine, ${ }^{32,33}$ and dehydroabietylamine ${ }^{34}$ have been reported as amine sources to synthesize benzoxazine resins.

Resveratrol is a triphenol compound that is extracted from grapes, pines, legumes, and other plants and has been extensively studied since 1940 when it was isolated for the first time from white hellebore. ${ }^{35}$ Given its simple chemical structure, resveratrol is straightforwardly synthesized through a variety of different synthetic approches. ${ }^{36-38}$ As each resveratrol molecule contains three phenolic hydroxyl groups,

Received: January 29, 2019

Revised: April 22, 2019

Published: May 8, 2019 
Scheme 1. Synthesis of the Biobased Trioxazine Benzoxazine Monomer (RES-fa)

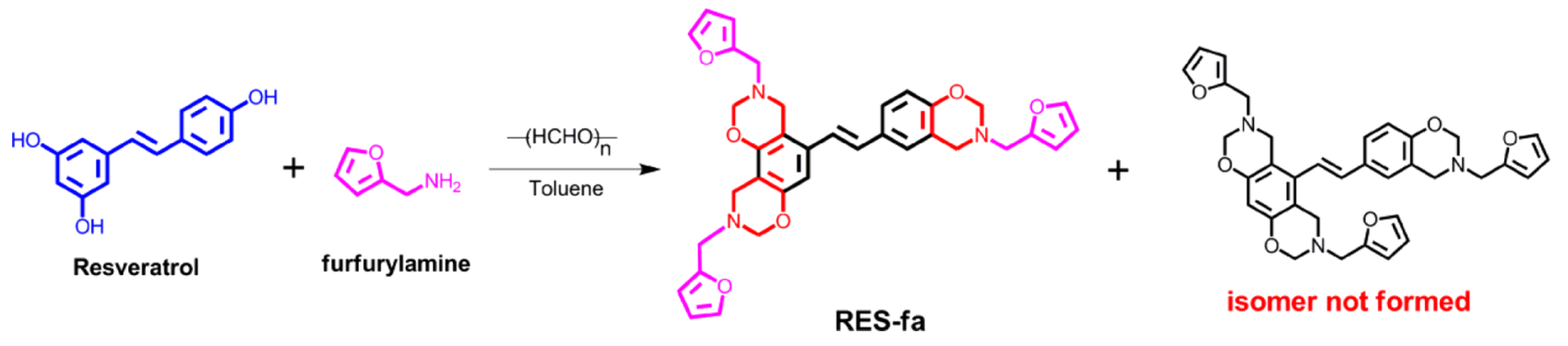

it appears to be an ideal compound for producing thermosetting resins. A series of biobased epoxy resins were synthesized via resveratrol derived from tannins. ${ }^{39}$ The resveratrol-based epoxy resins exhibited good thermal stability and excellent mechanical properties, making them a promising alternative to petroleum-based epoxy resins. In addition, Cash et al. reported the synthesis of tricyanate esters from resveratrol and dihydroresveratrol. ${ }^{40}$ Although these resveratrol-based cyanate esters showed excellent thermal properties, a relative high polymerization temperature $\left(350{ }^{\circ} \mathrm{C}\right)$ had to be applied to achieve fully polymerized thermosets. Clearly, the previously mentioned studies indicate the possibility for obtaining resveratrol-containing high-performance thermosets.

In the current study, we report a novel fully biobased trioxazine benzoxazine resin using resveratrol as the phenolic compound and furfurylamine as the amine, both being obtained from natural renewable resources. It is noteworthy to mention that the amine used in this investigation, furfurylamine, is easily obtained from furfural, which has been listed as a top 10 value-added biobased chemical by the US Department of Energy. ${ }^{41}$ To the best of our knowledge, this is the first report showing the synthesis of a trioxazine benzoxazine using natural renewable resources. In addition, the chemical structure of the obtained benzoxazine monomer has been characterized by Fourier transform infrared (FT-IR) as well as ${ }^{1} \mathrm{H}$ and ${ }^{13} \mathrm{C}$ nuclear magnetic resonance (NMR) spectroscopies and two-dimensional ${ }^{1} \mathrm{H}-{ }^{1} \mathrm{H}$ nuclear Overhauser effect spectroscopy (2D NOESY). The ring-opening polymerization behavior has been studied by differential scanning calorimetry (DSC) and in situ FT-IR. Moreover, the thermal properties and flame-retardant performance of the corresponding polybenzoxazine have also been evaluated. These results suggest the high possibility of obtaining by design high performance as well as fire resistant thermosets via fully biobased benzoxazines using resveratrol and furfurylamine as natural renewable resources in addition to the traditional resins coming from petrochemistry.

\section{EXPERIMENTAL SECTION}

Materials. Resveratrol (99\%) was purchased from Aladdin Reagent, China, and used as received. Furfuryalmine (99\%), paraformaldehyde (96\%), toluene, and sodium hydroxide $(\mathrm{NaOH})$ were obtained from Energy Reagent, China, and used as received.

Characterization Methods. Fourier transform infrared (FT-IR) spectra of benzoxazine monomer and polymerized samples were all recorded using an FT-IR spectrophotometer (Bomem, model Michelson MB 110). One dimensional (1D) ${ }^{1} \mathrm{H}$ nuclear magnetic resonance (NMR) spectra were acquired on a Bruker AVANCE II $400 \mathrm{MHz}$ NMR spectrometer. DMSO- $d_{6}$ was used as the solvent, while tetramethylsilane was used as an internal standard. ${ }^{1} \mathrm{H}$ NMR spectra were on average 64 transients. Elemental analysis was carried out on an Elementar Vario EL-III analyzer. $2 \mathrm{D}{ }^{1} \mathrm{H}-{ }^{1} \mathrm{H}$ nuclear
Overhauser effect spectroscopy (NOESY) was utilized as well to elucidate the chemical structure. Differential scanning calorimetry (DSC) was carried out on a NETZSCH DSC equipment (Model 204f1). The temperature ramp rate was $10{ }^{\circ} \mathrm{C} / \mathrm{min}$ under $\mathrm{N}_{2}$ atmosphere, with $60 \mathrm{~mL} / \mathrm{min}$ of $\mathrm{N}_{2}$ flow rate. Thermomechanical analysis (TMA) was carried out on a NETZSCH TMA/402F4 with 5 ${ }^{\circ} \mathrm{C} / \mathrm{min}$ of heating rate. The coefficient of thermal expansion (CTE) was calculated between 50 and $300{ }^{\circ} \mathrm{C}$. Thermogravimetric analysis (TGA) was carried out on a NETZSCH STA449-C equipment, from room temperature to $850{ }^{\circ} \mathrm{C}$, at a heating rate of $10{ }^{\circ} \mathrm{C} / \mathrm{min}$ and under $\mathrm{N}_{2}$. For activation energy study, heating rates of $5,15,20$, and $25{ }^{\circ} \mathrm{C} /$ min were also conducted in TGA measurements. A microscale combustion calorimeter (MCC; Fire Testing Technology), taking into consideration the ASTM 7309-2007a standard, was used to study the specific heat release rate ( $\mathrm{HRR}, \mathrm{W} / \mathrm{g}$ ) and the total heat release (THR, $\mathrm{kJ} / \mathrm{g}$ ). The MCC thermograms were recorded from 100 to $750{ }^{\circ} \mathrm{C}$, at $1{ }^{\circ} \mathrm{C} / \mathrm{s}$ as heating rate, under $80 \mathrm{~mL} / \mathrm{min}$ of $\mathrm{N}_{2}$ flow rate. A stream of $\mathrm{O}_{2}(20 \mathrm{~mL} / \mathrm{min})$ was mixed into the anaerobic thermal degradation products as the $\mathrm{N}_{2}$ gas stream prior to entering the combustion furnace. The combustion furnace temperature was set at $900{ }^{\circ} \mathrm{C}$.

Synthesis of Resveratrol-Based Benzoxazine Monomer (RES-fa). Resveratrol (1.14 g, $0.005 \mathrm{~mol})$, furfurylamine (1.46 g, $0.015 \mathrm{~mol})$, paraformaldehyde $(0.99 \mathrm{~g}, 0.033 \mathrm{~mol})$, and $35 \mathrm{~mL}$ of toluene were added into a $100 \mathrm{~mL}$ round-bottom flask equipped with a magnetic stirrer and a condenser. The mixture was stirred at $100{ }^{\circ} \mathrm{C}$ for $5 \mathrm{~h}$. After being cooled to room temperature, the reaction solution was washed three times with $3 \mathrm{~N} \mathrm{NaOH}$ aqueous solution and distilled water. The product was recrystallized from mixed solvents, acetone/toluene in a 1:1 ratio. After that, needle-like crystals of resveratrol-based benzoxazine were obtained (yield ca. $75 \%$ ). ${ }^{1} \mathrm{H}$ NMR (400 MHz, DMSO- $d_{6}$ ), ppm: $\delta=3.79,3.84,3.85$ (t, 6H, RN$\mathrm{CH}_{2}$-Fur), 3.86, 3.95, 4.02 (t, $6 \mathrm{H}, \mathrm{Ar}-\mathrm{CH}_{2}-\mathrm{N}$, oxazine), 4.78, 4,79, $4.86\left(\mathrm{t}, 6 \mathrm{H}, \mathrm{O}-\mathrm{CH}_{2}-\mathrm{N}\right.$, oxazine $), 6.29-6.30(\mathrm{~m}, 3 \mathrm{H}, \mathrm{RC}=\mathrm{CH}-\mathrm{CHR})$, 6.40-6.43 (m, 3H, CHR-CH=CHO), $6.68(\mathrm{~s}, 1 \mathrm{H}, \mathrm{Ar}), 6.75-6.77$ $(\mathrm{d}, 1 \mathrm{H}, \mathrm{CH}=\mathrm{CH}-\mathrm{Ar}), 6.88-6.92(\mathrm{~d}, 1 \mathrm{H}, \mathrm{Ar}), 6.92-6.95(\mathrm{~d}, 1 \mathrm{H}, \mathrm{Ar})$, 7.29 (s, $1 \mathrm{H}, \mathrm{Ar}), 7.34-7.36(\mathrm{~d}, 1 \mathrm{H}, \mathrm{Ar}-\mathrm{CH}=\mathrm{CH}), 7.60-7.63(\mathrm{~m}$, $3 \mathrm{H},-\mathrm{OCH}-\mathrm{CH})$. FT-IR spectra $(\mathrm{KBr}), \mathrm{cm}^{-1}: 1608 \quad(\mathrm{C}=\mathrm{C}$ stretching), 1501 ( $\mathrm{C}=\mathrm{C}$ stretching of furfural ring), 1227 ( $\mathrm{C}-\mathrm{O}-$ $\mathrm{C}$ antisymmetric stretching), 920 (benzoxazine related band). Elemental Analysis Calcd for $\mathrm{C}_{35} \mathrm{H}_{33} \mathrm{~N}_{3} \mathrm{O}_{6}: \mathrm{C}, 71.05 ; \mathrm{H}, 5.62 ; \mathrm{N}$, 7.10. Found: C, 71.01; H, 5.66; N, 7.06.

Polymerization of RES-fa. Polymerization of RES-fa to obtain poly(RES-fa) was performed following a stepwise process. Specifically, RES-fa was polymerized in a glass mold by carrying out five polymerizations steps of $1 \mathrm{~h}$ each at the following temperatures: 160, $180,200,220$, and $240{ }^{\circ} \mathrm{C}$.

\section{RESULTS AND DISCUSSION}

Synthesis and Structural Characterization. Synthetic protocols for obtaining furfurylamine-containing benzoxazines have been widely reported. ${ }^{32,33}$ However, the synthesis of benzoxazines using resveratrol as the phenolic moiety to be reacted in combination with furfurylamine has never been investigated. As described in the Experimental Section, the 
newly obtained biobased trioxazine benzoxazine monomer, RES-fa, was synthesized using resveratrol, furfurylamine, and paraformaldehyde (Scheme 1). The chemical structure of RESfa was characterized by FT-IR and ${ }^{1} \mathrm{H}$ NMR analyses.

A number of infrared absorption bands are highlighted in Figure 1 and used to verify the presence of the oxazine rings

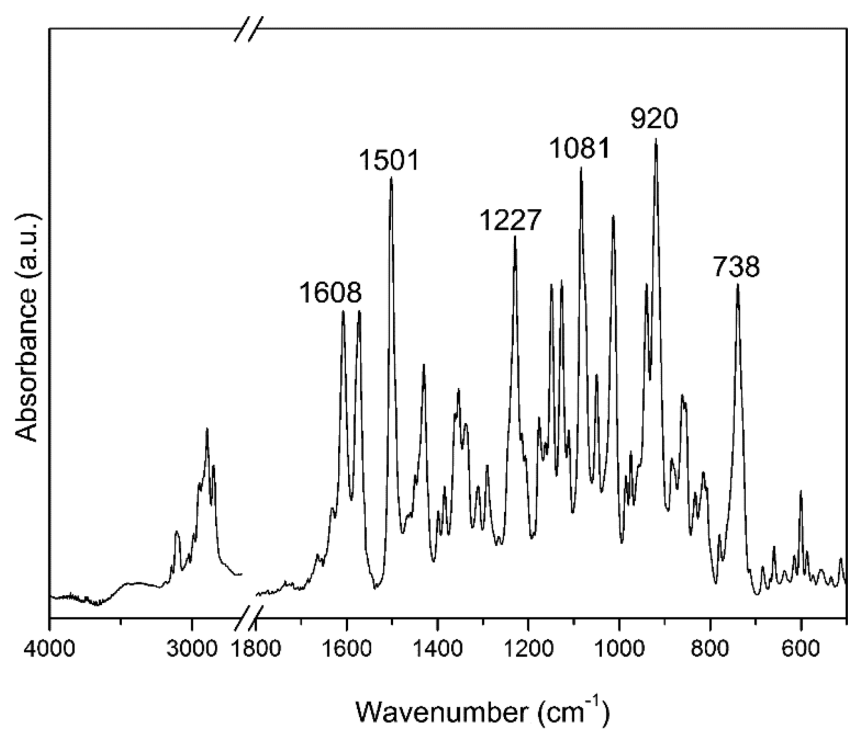

Figure 1. FT-IR spectrum of RES-fa.

and the resveratrol and furan moieties in the molecular structure of the product. Thus, the characteristic band at 1608 $\mathrm{cm}^{-1}$ is due to the strong $\mathrm{C}=\mathrm{C}$ stretching vibration of the vinyl group of resveratrol, while the presence of the oxazine ring in the monomers is indicated by the band centered at $1227 \mathrm{~cm}^{-1}$ due to the asymmetric aromatic-aliphatic ether (C-O-C) antisymmetric stretching modes. ${ }^{42}$ The typical absorption mode for oxazine ring is observed at $920 \mathrm{~cm}^{-1}$. 43 The successful incorporation of the furan group as a constitutive moiety of the benzoxazine structure is indicated by the characteristic bands observed at 1501, 1081, and 738 $\mathrm{cm}^{-1}$, which are assigned to $\mathrm{C}=\mathrm{C}$ stretching, $\mathrm{C}-\mathrm{O}$ antisymmetric stretching, and $\mathrm{C}-\mathrm{H}$ out-of-plane in-phase wagging, respectively. Moreover, the absence of any typical signal related to hydrogen bonding indicates that no free $-\mathrm{OH}$ remained after the synthesis procedure, thus strongly indicating a full reaction toward trioxazine benzoxazine formation.

The FT-IR analysis suggests a successful synthesis of the targeted benzoxazine. However, as shown in Scheme 1, the oxazine ring formation reaction starting from resveratrol might generate two different isomers. Since all of the assigned peaks have a correct aspect ratio, and no extra overlapping or noticeable overbroadening of any band were observed in FTIR spectrum, it seems that only one of the two possible isomers of RES-fa was formed following the synthetic procedure carried out in the present work. Nevertheless, FT-IR results are not conclusive or detailed enough concerning the information on which of the two possible isomer was in fact obtained.

${ }^{1} \mathrm{H}$ NMR analysis was carried out to obtain further structural information. Herein, the most important information used to identify the isomer obtained is provided by the signals related to the methylene protons in the oxazine rings. Generally, the characteristic ${ }^{1} \mathrm{H}$ NMR resonance pair for $\mathrm{O}-\mathrm{CH}_{2}-\mathrm{N}$ and the Ar- $\mathrm{CH}_{2}-\mathrm{N}$ in typical benzoxazine compounds consists of two singlets with a frequency separation of around $0.8-0.9 \mathrm{ppm}$ in the spectral region between 3.0 and 5.5 ppm. ${ }^{3,4}$ However, as seen in Figure 2, the characteristic proton resonances associated to the $\mathrm{O}-\mathrm{CH}_{2}-\mathrm{N}$ and $\mathrm{Ar}-\mathrm{CH}_{2}-\mathrm{N}$ groups from the oxazine rings of RES-fa are observedat $4.86,4,79$ and $4.78 \mathrm{ppm}$ and $4.02,3.95$, and $3.86 \mathrm{ppm}$, respectively. There is a clear overlapping observed between a signal associated to one of the Ar- $\mathrm{CH}_{2}-\mathrm{N}$ groups and two of the $\mathrm{RN}-\mathrm{CH}_{2}$-Fur, specifically $3.86,3.85$, and 3.84 , respectively. Furthermore, one more signal related to a typical resonance of a methylene group belonging to the $\mathrm{RN}-\mathrm{CH}_{2}$-Fur from the furfurylamine moieties located at $3.79 \mathrm{ppm}$ is seen in the spectrum. The integration ratio for these sets of protons perfectly corresponds to 2 hydrogen atoms per signal, thus totalizing 6 . It is important to mention that no other signal is observed in this spectral region associated to any other proton. Thus, the presence of these three sets of characteristic methylene proton resonances exhibiting the right integration ratio strongly supports the existence of only one of the possible isomers of RES-fa bearing the asymmetric chemical structure shown in Scheme 1. If, on
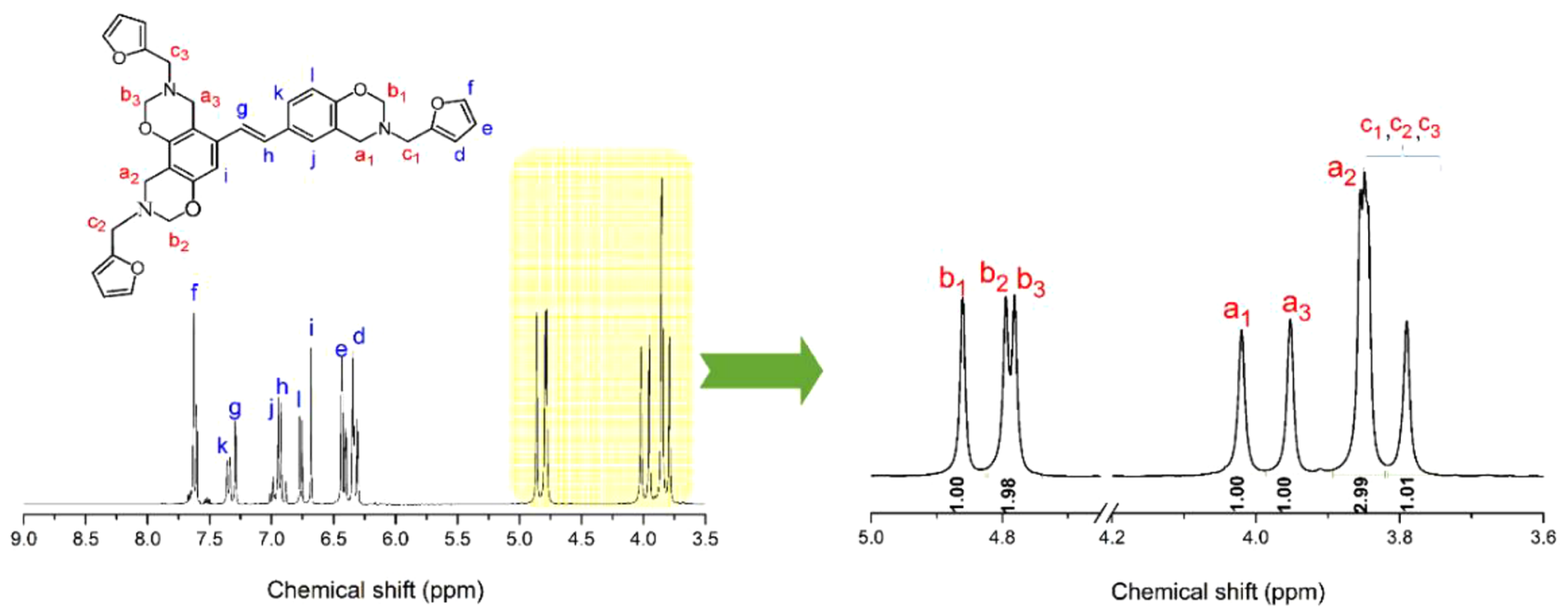

Figure 2. ${ }^{1} \mathrm{H}$ NMR spectrum of RES-fa in DMSO- $d_{6}$. The expanded region between 3.6 and $5.0 \mathrm{ppm}$ shows the three types of characteristic resonances for the methylene groups, OC- $\mathrm{H}_{2}-\mathrm{N}, \mathrm{Ar}-\mathrm{CH}_{2}-\mathrm{N}$, and $\mathrm{RN}-\mathrm{CH}_{2}-\mathrm{Fur}$. 

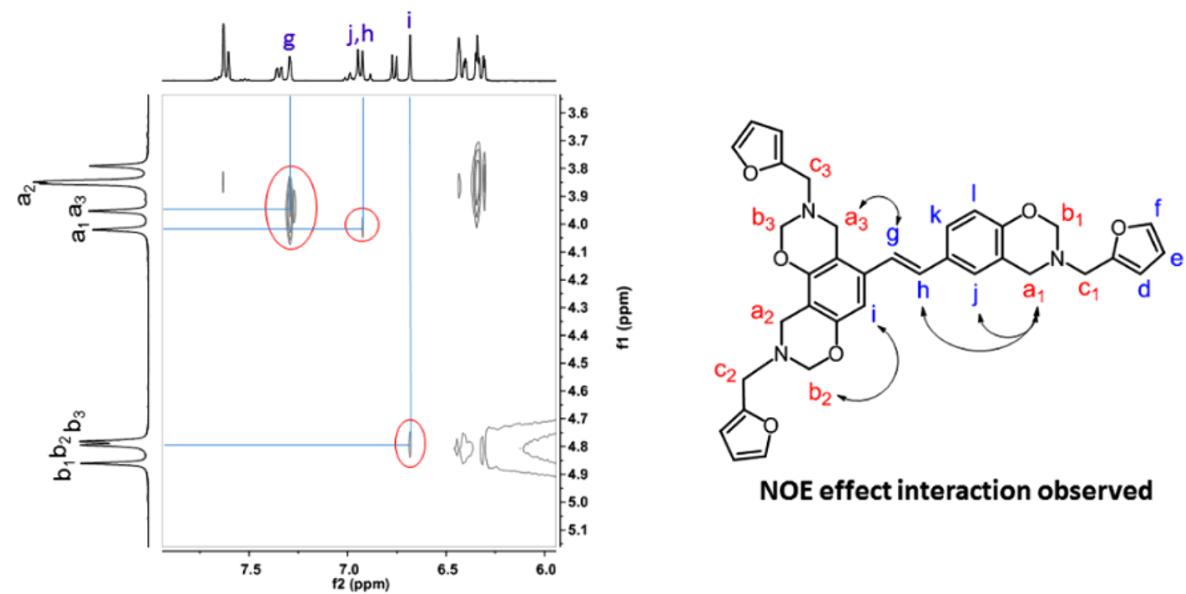

NOE effect interaction observed

Figure 3. $2 \mathrm{D}{ }^{1} \mathrm{H}-{ }^{1} \mathrm{H}$ NOESY NMR spectrum of RES-fa, region between 3.5 and $5.2 \mathrm{ppm}$ for $\mathrm{f} 1$ and 6.0 and $7.8 \mathrm{ppm}$ for $\mathrm{f} 2$, showing NOE interactions that helped to identify the isomer obtained.

the contrary, the two oxazine rings formed in the same benzene ring would have formed a symmetric structure, only two sets of methylene signals would have been observed in the ${ }^{1} \mathrm{H}$ NMR spectrum. Moreover, a mixture of both sets of signals for the oxazine ring protons would have been observed if both isomers would have been formed, with an integration ratio corresponding to the percentage in which the isomers would have been present. Thus, this ${ }^{1} \mathrm{H}$ NMR analysis shows that only one isomer has been obtained upon the herein reported experimental reaction conditions and supports the chemical structure proposed for RES-fa as shown in Scheme 1.

A complementary spectroscopic study was then performed to assign the three sets of methylene protons from the oxazine rings. Figure 3 shows the $2 \mathrm{D}{ }^{1} \mathrm{H}-{ }^{1} \mathrm{H}$ NOESY spectrum of RES-fa. NOE interactions can be seen in various manners following different orders. Nevertheless, one important signal is clearly observed showing NOE interaction generated for $\mathrm{H}_{\mathrm{g}}$. The signal related to $\mathrm{H}_{\mathrm{g}}$ is seen as a doublet in the ${ }^{1} \mathrm{H}$ NMR spectrum since it is a characteristic vinylic proton, Figure 2. Only one interaction for $\mathrm{H}_{\mathrm{g}}$ is detected with an aliphatic proton, specifically $\mathrm{H}_{\mathrm{a} 3}$. At the same time, another $\mathrm{NOE}$ interaction is observed between protons $H_{h}$ and $H_{a 1}$. Simultaneously, the signal from $\mathrm{H}_{\mathrm{i}}$ observed as an aromatic singlet exhibits an interaction with proton $\mathrm{H}_{\mathrm{b} 2}$. Therefore, this combined set of observed NOE interactions for these proton signals are used to unambiguously demonstrate the correct chemical structure of RES-fa as shown in Scheme 1.

Thermal Behavior and Polymerization of Benzoxazine Monomer RES-fa. The DSC thermogram of RES-fa is shown in Figure 4, where two thermal events are seen. The first one is an endothermic process with its minimum located at $126^{\circ} \mathrm{C}$, which is assigned to the melting of the benzoxazine monomer crystals. The sharpness of this endothermic peak puts in evidence the high purity of RES-fa, as confirmed by the elemental analysis results; see the Experimental Section. The second thermal event is exothermic and attributed to the ringopening polymerization, with onset at $193{ }^{\circ} \mathrm{C}$ and maximum at $229^{\circ} \mathrm{C}$. The polymerization temperature observed for RES-fa is much lower than those of other benzoxazine monomers without incorporating any special functionalities. ${ }^{5}$ In addition, RES-fa shows a heat of polymerization value of $324 \mathrm{~J} / \mathrm{g}$. It is worth noticing that this value is significantly higher than for many other reported benzoxazines. ${ }^{44}$ This difference might be caused by the complex, tensioned, and multifunctional

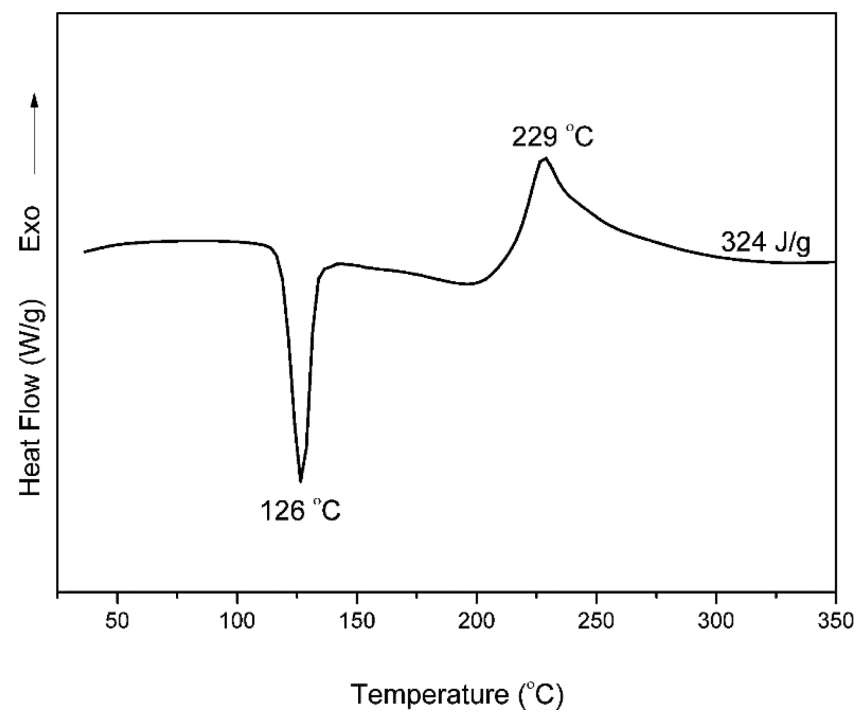

Figure 4. DSC thermogram of the trioxazine benzoxazine monomer RES-fa.

chemical structure of RES-fa, which bears three oxazine rings into the same molecule having two of them in fact fused to the same aromatic benzene ring.

The polymerization of RES-fa was carried out following a five-step process as specified in the Experimental Section. With an interest in evaluating the efficiency of each polymerization step as well as the polymerization process as a whole, different samples were prepared and studied. The results are presented in Figure 5.

As can be seen in Figure 5, after the first polymerization step (isothermal heating at $160{ }^{\circ} \mathrm{C}$ for $1 \mathrm{~h}$ ) the endothermic peak of RES-fa disappeared completely, the exothermic peak maximum shifted to a lower temperature $\left(222^{\circ} \mathrm{C}\right)$, and the heat of polymerization decreased $(257 \mathrm{~J} / \mathrm{g})$. Conversely, a systematic increase of the polymerization temperature is observed in the thermograms of the second, third, and forth polymerization steps, 237, 245, and $264{ }^{\circ} \mathrm{C}$, respectively. This shifting of the polymerization temperature was accompanied by a marked reduction of the heat of polymerization measured after each polymerization step carried out. Finally, no thermal events are detected in the thermogram corresponding to the fifth polymerization step. 


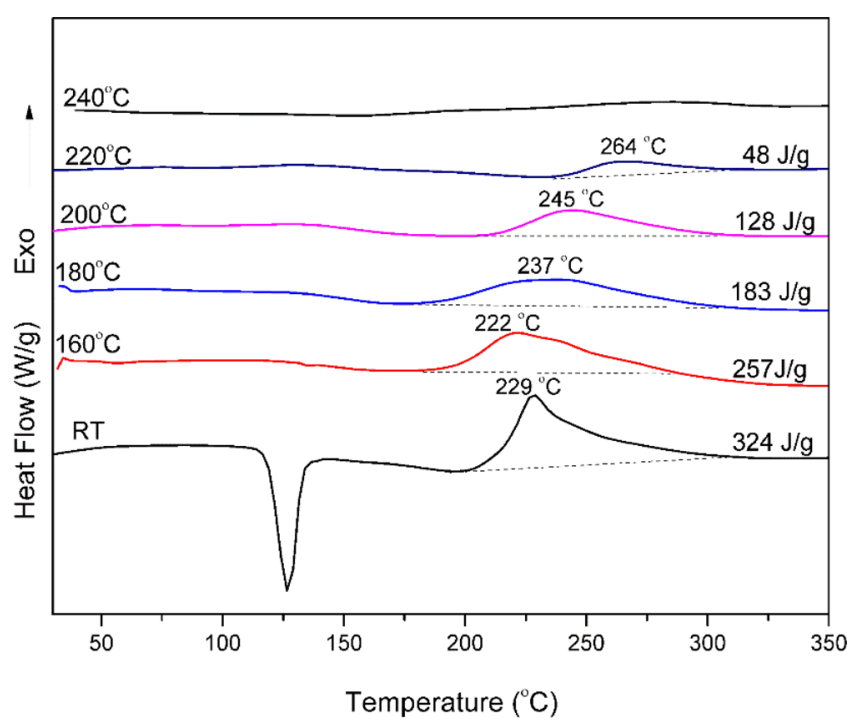

Figure 5. DSC thermograms of RES-fa during the step-by-step polymerization reaction.

These DSC results indicate that the ring-opening polymerization reaction is completed after the fifth polymerization step. Furthermore, it is important to highlight that RES-fa can easily be transformed into a more practical and better processingfriendly state by applying just the first thermal treatments, where no more crystals are present and a so-called prepolymer is obtained. This extremely straightforward approach can be performed with the pure compound as well as in the production of composite materials needing post-thermal treatments.

To gain deeper understanding on the ring-opening polymerization of RES-fa at the molecular level, an in situ FT-IR qualitative analysis was carried out as seen in Figure 6. The

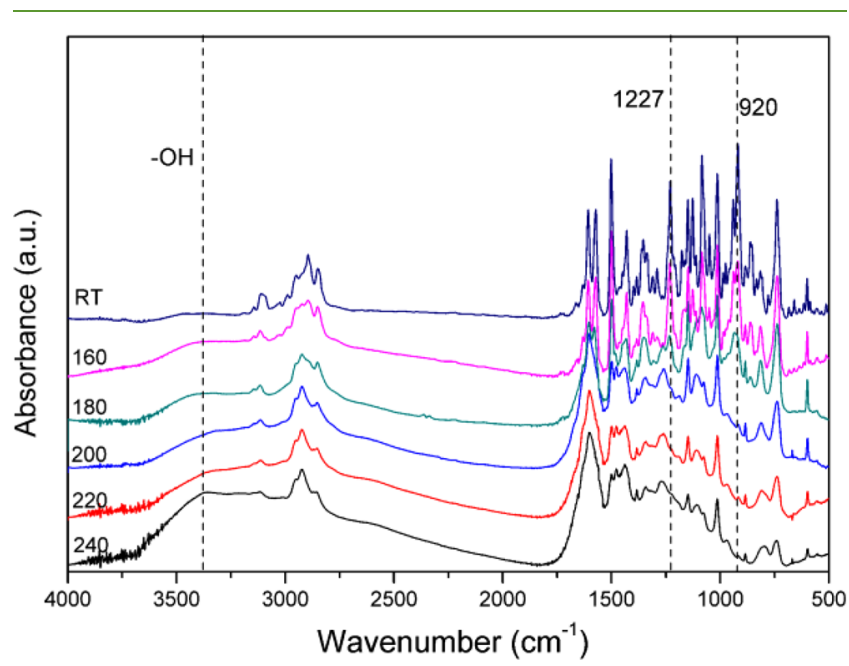

Figure 6. In situ FT-IR spectra of RES-fa after each polymerization step.

typical absorption bands at 1227 and $920 \mathrm{~cm}^{-1}$ are utilized to investigate the ring-opening polymerization of the oxazine rings of RES-fa. The gradual intensity decrease of these bands as a function of the temperature applied in each polymerization step followed by their complete disappearance, after the fifth thermal treatment, strongly suggests full reaction of the oxazine rings. In addition, there is a simultaneous gradual appearance of broad bands associated to phenolic $-\mathrm{OH}$ groups around $3400 \mathrm{~cm}^{-1}$. The characteristic band with broad background observed between 3400 to $2200 \mathrm{~cm}^{-1}$ is originated by the chelated phenolic groups involved in intramolecular sixmembered hydrogen bonds with the nitrogen atoms belonging to the polymer backbone. ${ }^{4}$

Combination of the information obtained from the previous results by DSC and in situ FT-IR analyses, in addition to having worked with an extremely pure sample as evidenced by DSC and elemental analysis, leads to the proposed thermal ring-opening polymerization mechanism depicted in Scheme 2.

Thermal Properties of Polybenzoxazine poly(RES-fa). TMA was used to study the thermomechanical property of poly(RSE-fa). Figure 7 shows the graphic generated by plotting the expansion ratio as a function of the temperature. The coefficient of thermal expansion (CTE) obtained by analyzing the graphic is $36.2 \mathrm{ppm} /{ }^{\circ} \mathrm{C}$. This $\mathrm{CTE}$ value obtained for poly(RES-fa) is much lower compared with the $70 \mathrm{ppm} /{ }^{\circ} \mathrm{C}$ reported for a typical bisphenol A epoxy resin thermoset. ${ }^{45}$ In addition, a crossing point is observed at 122 ${ }^{\circ} \mathrm{C}$, by connecting the straight lines extrapolated from 30 to 80 ${ }^{\circ} \mathrm{C}$ with the one extrapolated from 300 to $160{ }^{\circ} \mathrm{C}$, which might be due to a $\beta$ transition of poly(RES-fa). Moreover, TMA curves are also used to calculate the $T_{\mathrm{g}}$ of the studied samples. Thus, the $T_{\mathrm{g}}$ value found for poly(RES-fa) is $312{ }^{\circ} \mathrm{C}$ as shown in Figure 7 , indicating a good adaptability of this polymer toward high performance applications.

Thermogravimetric analysis (TGA) was used to quantitatively evaluate the thermal stability of poly(RES-fa), and the results are shown in Figure 8. The temperatures at which a weight loss of $5 \%$ and $10 \%$ are defined as $T_{\mathrm{d} 5}$ and $T_{\mathrm{d} 10}$ and were measured from the TGA thermogram of poly(RES-fa) showing values of 346 and $403{ }^{\circ} \mathrm{C}$, respectively. As expected, the incorporation of three oxazine rings as part of the very same compound (RES-fa) significantly improved the thermal stability of its corresponding thermosets (poly(RES-fa)) when compared with that of typical bis-benzoxazines, such as BA-a resin. ${ }^{46}$ This might be explained by a higher crosslinking density. To complement these results, the char yield (Yc) of poly(RES-fa) was also calculated from the TGA thermogram, exhibiting the high value of $64 \%$ at $800{ }^{\circ} \mathrm{C}$.

Because of the intention of generating biobased polybenzoxazines to develop high-performance materials, it was necessary to quantify the activation energy $\left(E_{\mathrm{a}}\right)$ for the thermal degradation reaction of poly(RES-fa). To achieve this goal, it was first necessary to investigate the TGA profiles of a series of thermograms of poly(RES-fa) carried out at different heating rates. Figure 9 shows the TGA thermograms obtained at heating rates of $5,10,15,20$, and $25{ }^{\circ} \mathrm{C} / \mathrm{min}$.

The apparent activation energy for the degradation reaction was determined using the well-known Flynn-Wall-Ozawa methods. ${ }^{47,48}$ Thus, the $E_{\mathrm{a}}$ can be calculated by eq 1 as follows

$$
\frac{\mathrm{d}(\log \beta)}{\mathrm{d}(1 / T)}=-0.4567 \frac{E_{\mathrm{a}}}{R}
$$

where the heating rate is represented by $\beta, T$ is the temperature at a given conversion $\alpha$, and $R$ is the gas constant.

Figure 10 shows the plot of $\ln (\beta)$ against $1 / T$ for poly(RESfa) according to the Flynn-Wall-Ozawa method. The calculated $E_{\mathrm{a}}$ values are summarized in Table 1 . As can be seen in Table 1 , the activation energy slightly increases as the conversion (degradation reaction) increases from $5 \%$ to $25 \%$, 
Scheme 2. Proposed Thermal Ring-Opening Polymerization of RES-fa

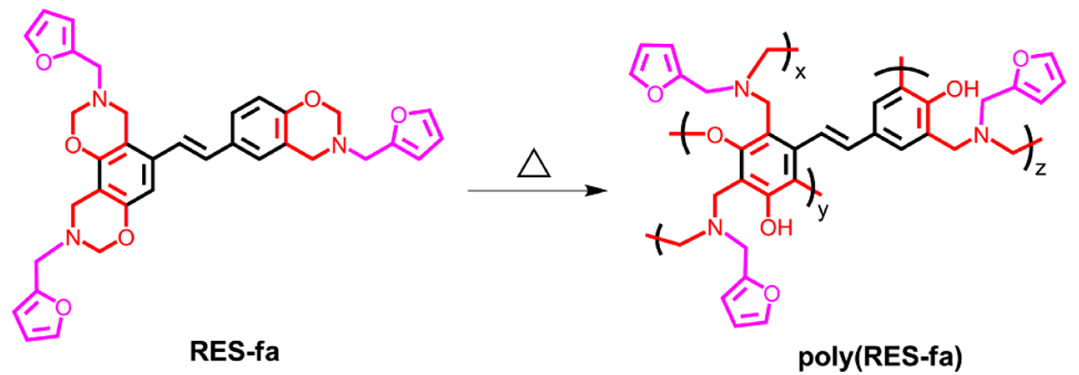

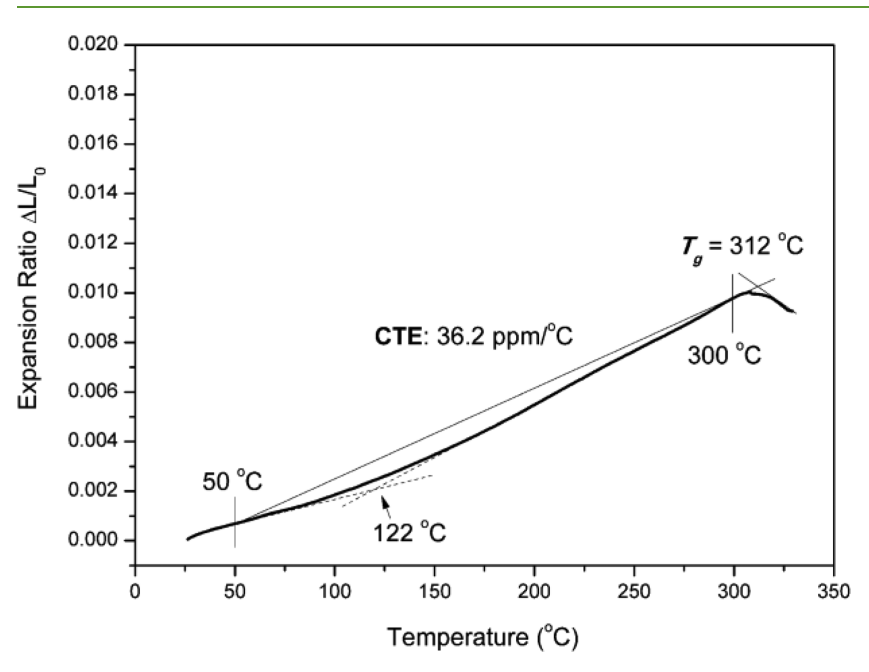

Figure 7. Thermomechanical analysis of thermoset film of poly(RESfa).

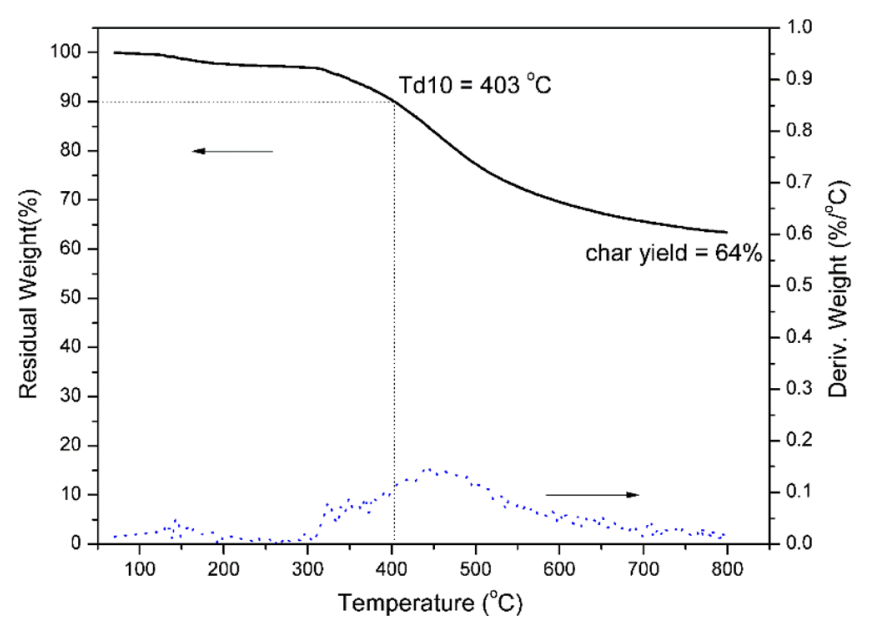

Figure 8. TGA (- $)$ and DTG ( $\cdots)$ thermograms of poly(RES-fa).

suggesting that poly(RES-fa) becomes more difficult to degrade as the degradation proceeds. The result of this activation energy study might be rationalized as if a more thermally stable crosslinked network might be formed via molecular rearrangement side reactions accompanying the degradation process of poly(RES-fa). It is worth highlighting at this point that the furan groups have been demonstrated to participate in chemical reaction increasing the crosslinking density of other polybenzoxazine systems. ${ }^{29}$

Microscale combustion calorimetry (MCC) was used to quantitatively evaluate properties related to the flammability of poly(RES-fa), such as the heat release rate (HRR), heat

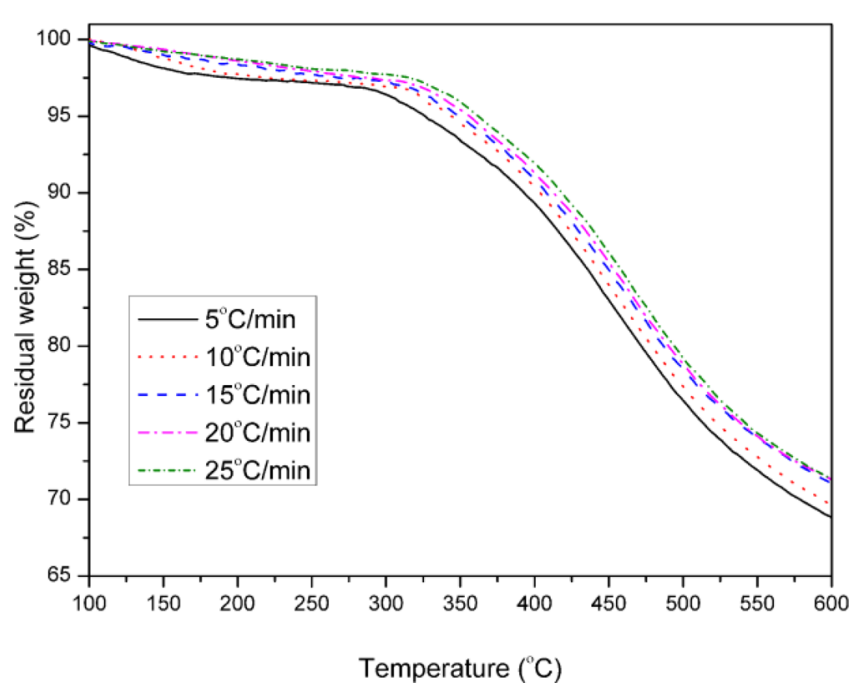

Figure 9. TGA thermograms of poly(RES-fa) at different heating rates.

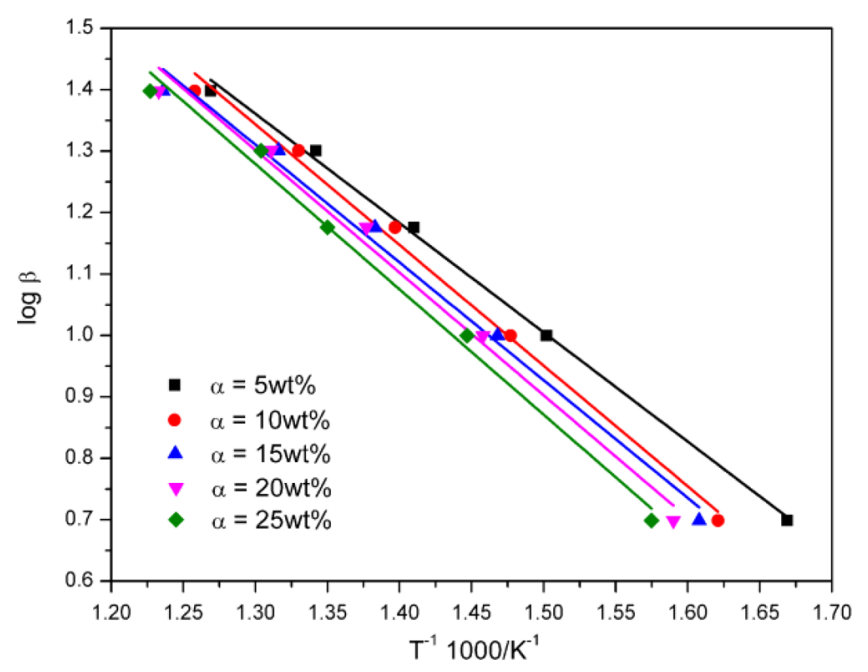

Figure 10. Plots generated by the Flynn-Wall-Ozawa method to determine the activation energy for the degradation reaction of poly(RES-fa).

release capacity (HRC), and total heat release (THR). Typically, the specific HRR is obtained dividing $\mathrm{d} Q / \mathrm{d} t$ at each time interval by the initial sample mass. Knowing the HRR is very important because the heat release capacity (HRC) is straightforwardly calculated dividing the HRR maximum by the heating rate. In a general manner, HRC is utilized as an effective standard for evaluating thermal combustion, which is regarded as a powerful predictor for 
Table 1. Activation Energy Values for the Degradation Reaction of poly(RES-fa) at Different Conversions

\begin{tabular}{cc} 
conversion $(\alpha)(\mathrm{wt} \%)$ & $E_{\mathrm{a}}(\mathrm{kJ} / \mathrm{mol})$ \\
5 & 32.4 \\
10 & 33.7 \\
15 & 34.2 \\
20 & 34.7 \\
25 & 36.6 \\
\hline
\end{tabular}

the flammability of any given materials. ${ }^{49}$ As shown in Figure 11 , poly(RES-fa) samples were measured at $1 \mathrm{~K} / \mathrm{s}$ of heating rate at the temperature range between 100 and $750{ }^{\circ} \mathrm{C}$.
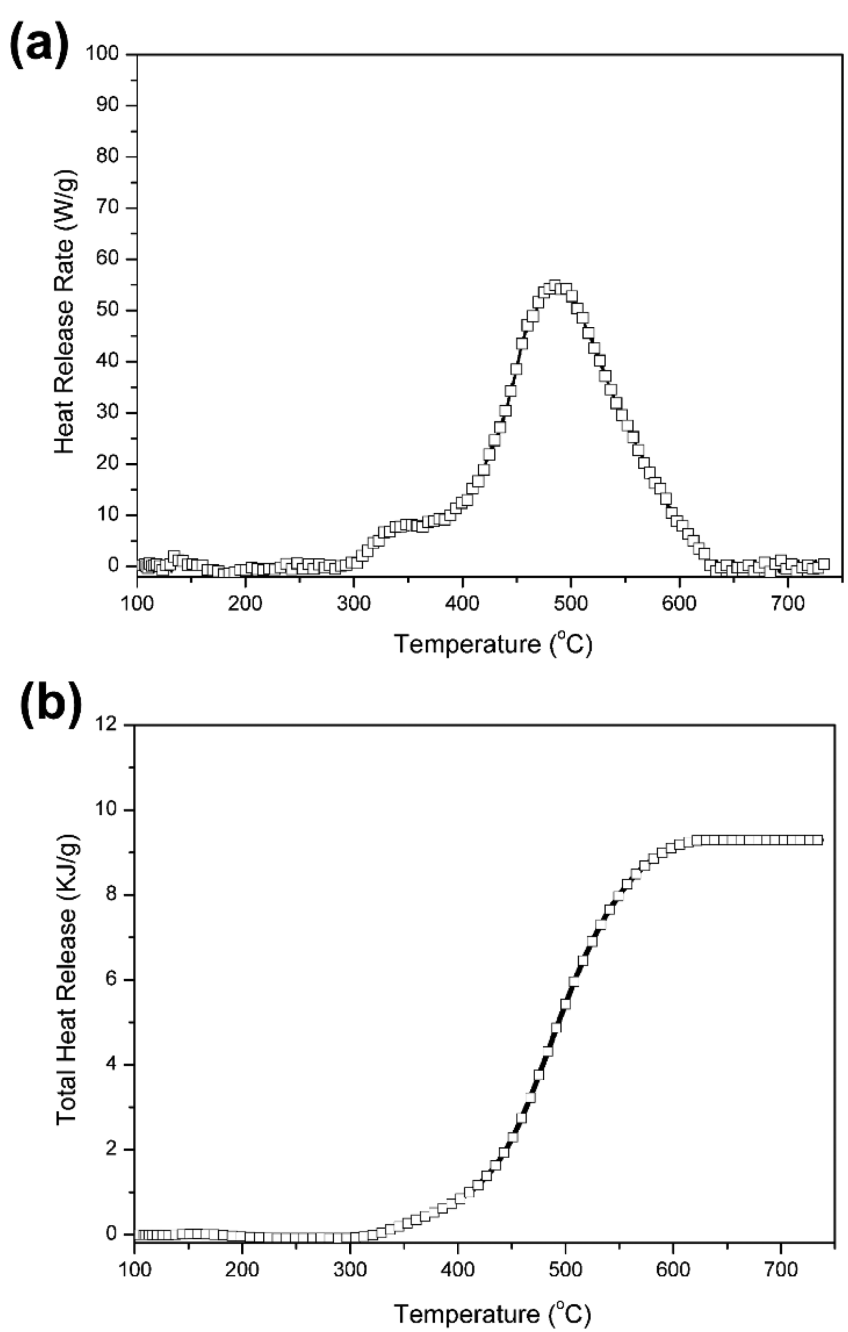

Figure 11. Microscale combustion calorimetric (MCC) analysis of poly(RES-fa). Plots of (a) heat release rate and (b) total heat release as a function of the temperature in both cases.

Figure 11a shows the graphic of HRR as a function of the temperature, where the HRR maximum is observed to be at $489{ }^{\circ} \mathrm{C}$. Figure $11 \mathrm{~b}$ shows that the plateau of the THR is reached at the temperature of $623{ }^{\circ} \mathrm{C}$. Thus, using this information obtained from the MCC studies allowed us to calculate the HRC and THR of poly(RES-fa), which were found to be $54 \mathrm{~J} \mathrm{~g}^{1-} \mathrm{K}^{-1}$ and $9.3 \mathrm{KJ} \mathrm{g}^{-1}$, respectively. The HRC value for poly(RES-fa) is even lower than those of polybenzoxazines obtained upon polymerization of $o$-amide and $o$-imide functional benzoxazine monomers. ${ }^{9,44}$ Typically, lower values of HRC or THR reveal a higher flame resistance. For instance, materials exhibiting HRC values lower than $300 \mathrm{~J}$ $\mathrm{g}^{-1} \mathrm{~K}^{-1}$ are regarded as self-extinguishing, whereas those with HRC values below $100 \mathrm{~J} \mathrm{~g}^{-1} \mathrm{~K}^{-1}$ are recognized as nonignitable. $^{50}$ The data collected in this work related to thermal and fire properties of poly(RES-fa) are summarized in Table 2, which demonstrates the high thermal stability and

Table 2. Thermal- and Fire-Related Properties of poly(RESfa)

\begin{tabular}{|c|c|c|c|c|c|c|}
\hline sample & $\begin{array}{c}T_{\mathrm{g}} \\
\left({ }^{\circ} \mathrm{C}\right)\end{array}$ & $\begin{array}{r}T_{\mathrm{d} 5} \\
\left({ }^{\circ} \mathrm{C}\right)\end{array}$ & $\begin{array}{l}T_{\mathrm{d} 10} \\
\left({ }^{\circ} \mathrm{C}\right)\end{array}$ & $\begin{array}{c}\mathrm{Yc} \\
\text { (wt \%) }\end{array}$ & $\underset{\left(\mathrm{J} \mathrm{g}^{1-} \mathrm{K}^{-1}\right)}{\mathrm{HRC}}$ & $\begin{array}{c}\text { THR } \\
\left(\mathrm{KJ} \mathrm{g}^{-1}\right)\end{array}$ \\
\hline $\begin{array}{l}\text { poly(RES- } \\
\text { fa) }\end{array}$ & 312 & 346 & 403 & 64 & 54 & 9.3 \\
\hline
\end{tabular}

low flammability of this new polybenzoxazine derived from fully biobased trioxazine benzoxazine monomer. Therefore, the combination of natural renewable resources, resveratrol and furfurylamine, contributes to the generation of a highperformance thermoset, thus making this material very attractive for applications requiring high thermal stability.

It is worth mentioning that the MCC results are in full agreement with those from the activation energy of the thermal degradation of poly(RES-fa). The fact that poly(RES-fa) becomes more and more difficult to degrade as the thermal degradation reaction proceeds is fully consistent with having obtained a self-extinguishing and even a nonignitable thermoset. These results are also in line with the TGA results previously discussed, which showed the high thermal stability of the synthesized poly(RES-fa), as observed by their high values of $T_{\mathrm{d} 5}, T_{\mathrm{d} 10}$, and Yc. Therefore, the combination of all obtained results puts in evidence the very high potential of this thermoset not only toward high-performance materials but also toward fire resistant applications.

\section{CONCLUSION}

A new trioxazine benzoxazine monomer, RES-fa, was successfully synthesized using resveratrol, furfurylamine, and formaldehyde as raw materials, making this resin fully biobased. RES-fa possess a relatively low melting temperature $\left(126{ }^{\circ} \mathrm{C}\right)$ and low ring-opening polymerization temperature $\left(229^{\circ} \mathrm{C}\right)$, which might be advantageous for its processability. In addition, the polybenzoxazine obtained, poly(RES-fa), from the herein synthesized fully biobased benzoxazine monomer exhibited high thermal stability, $T_{\mathrm{g}}$ of $312{ }^{\circ} \mathrm{C}, T_{\mathrm{d} 5}$ and $T_{\mathrm{d} 10}$ of 346 and $403{ }^{\circ} \mathrm{C}$, respectively, and a char yield of $64 \%$. Moreover, poly(RES-fa) was also shown to be a selfextinguishing and nonignitable material given the low heat release capacity ( $\mathrm{HRC}$ of $54 \mathrm{~J} \mathrm{~g}^{-1} \mathrm{~K}^{-1}$ ) as well as low total heat release (THR of $9.3 \mathrm{KJ} \mathrm{g}^{-1}$ ). The thermal properties of this fully biobased benzoxazine resin as well as those of the resulting thermoset are comparable with many petroleumbased conventional benzoxazines and polybenzoxazines. Therefore, the results of this study put in evidence that compounds coming from natural renewable resources can indeed be successfully applied as efficient raw materials for developing high-performance and fire-resistant materials.

\section{AUTHOR INFORMATION}

\section{Corresponding Authors}

*E-mail: zhangkan@ujs.edu.cn.

*E-mail: pxf106@case.edu. 


\section{ORCID $\odot$}

Kan Zhang: 0000-0003-4628-2704

Pablo Froimowicz: 0000-0003-1154-1024

\section{Notes}

The authors declare no competing financial interest.

\section{ACKNOWLEDGMENTS}

The financial support by the National Natural Science Foundation of China (51603093), the Science and Technology Agency of Jiangsu Province (BK 20160515), and the China Postdoctoral Science Foundation (2016M600369 and 2018T110451) are gratefully acknowledged. P.F. is a member of the Scientific and Technological Researcher Career at CONICET (Argentina).

\section{REFERENCES}

(1) Ning, X.; Ishida, H. Phenolic materials via ring-opening polymerization: Synthesis and characterization of bisphenol-A based benzoxazines and their polymers. J. Polym. Sci., Part A: Polym. Chem. 1994, 32, 1121-1129.

(2) Ghosh, N. N.; Kiskan, B.; Yagci, Y. Polybenzoxazines-new high performance thermosetting resins: synthesis and properties. Prog. Polym. Sci. 2007, 32, 1344-1391.

(3) Ishida, H.; Agag, T. Handbook of Benzoxazine Resins; Elsevier: Amsterdam, 2011.

(4) Ishida, H.; Froimowicz, P. Advanced and Emerging Polybenzoxazine Science and Technology; Elsevier: Amsterdam, 2017.

(5) Han, L.; Salum, M. L.; Zhang, K.; Froimowicz, P.; Ishida, H. Intrinsic self-initiating thermal ring-opening polymerization of 1, 3benzoxazines without the influence of impurities using very high purity crystals. J. Polym. Sci., Part A: Polym. Chem. 2017, 55, 34343445.

(6) Ohashi, S.; Iguchi, D.; Heyl, T. R.; Froimowicz, P.; Ishida, H. Quantitative studies on the p-substituent effect of the phenolic component on the polymerization of benzoxazines. Polym. Chem. 2018, 9, 4194-4204.

(7) Sini, N. K.; Endo, T. Toward elucidating the role of number of oxazine rings and intermediates in the benzoxazine backbone on their thermal characteristics. Macromolecules 2016, 49, 8466-8478.

(8) Deliballi, Z.; Kiskan, B.; Yagci, Y. Main-chain benzoxazine precursor block copolymers. Polym. Chem. 2018, 9, 178-183.

(9) Agag, T.; Liu, J.; Graf, R.; Spiess, H. W.; Ishida, H. Benzoxazole resin: A novel class of thermoset polymer via smart benzoxazine resin. Macromolecules 2012, 45, 8991-8997.

(10) Zhang, K.; Han, L.; Froimowicz, P.; Ishida, H. A smart latent catalyst containing o-trifluoroacetamide functional benzoxazine: precursor for low temperature formation of very high Performance polybenzoxazole with low dielectric constant and high thermal stability. Macromolecules 2017, 50, 6552-6560.

(11) Wu, J.; Xi, Y.; McCandless, G. T.; Xie, Y.; Menon, R.; Patel, Y.; Yang, D. J.; Iacono, S. T.; Novak, B. M. Synthesis and characterization of partially fluorinated polybenzoxazine resins utilizing octafluorocyclopentene as a versatile building block. Macromolecules 2015, 48, 6087-6095

(12) Wang, C. F.; Su, Y. C.; Kuo, S. W.; Huang, C. F.; Sheen, Y. C.; Chang, F. C. Low-surfance-free-energy materials based on polybenzoxazines. Angew. Chem., Int. Ed. 2006, 45, 2248-2251.

(13) Kuo, S. W.; Wu, Y. C.; Wang, C. F.; Jeong, K. U. Preparing Low-surface-energy polymer materials by minimizing intermolecular hydrogen-bonding interactions. J. Phys. Chem. C 2009, 113, 2066620673.

(14) Liao, C. S.; Wang, C. F.; Lin, H. C.; Chou, H. Y.; Chang, F. C. Tuning the surface free energy of polybenzoxazine thin films. J. Phys. Chem. C 2008, 112, 16189-16191.

(15) Brown, E. A.; Rider, D. A. Pegylated polybenzoxazine networks with increased thermal stability from miscible blends of tosylated poly(ethylene glycol) and a benzoxazine monomer. Macromolecules 2017, 50, 6468-6481.

(16) El-Mahdy, A. F. M.; Kuo, S. W. Direct synthesis of poly(benzoxazine imide) from an ortho-benzoxazine: Its thermal conversion to highly cross-linked polybenzoxazole and blending with poly(4-vinylphenol). Polym. Chem. 2018, 9, 1815-1826.

(17) Moore, C. J. Synthetic polymers in the marine environment: A rapidly increasing, long-term threat. Environ. Res. 2008, 108, 131139.

(18) Auvergne, R.; Caillol, S.; David, G.; Boutevin, B.; Pascault, J.-P. Biobased thermosetting epoxy: present and future. Chem. Rev. 2014, $114,1082-1115$.

(19) Liu, Y.; Cao, L.; Luo, J.; Peng, Y.; Ji, Q.; Dai, J.; Zhu, J.; Liu, X. Biobased nitrogen- and oxygen-codoped carbon materials for highperformance supercapacitor. ACS Sustainable Chem. Eng. 2019, 7, $2763-2773$.

(20) Dai, Y.; Teng, N.; Shen, X.; Liu, Y.; Cao, L.; Zhu, J.; Liu, X. Syntheis of biobased benzoxazines suitable for vacuum-assisted resin transfer molding process via introduction of soft silicon segment. Ind. Eng. Chem. Res. 2018, 57, 3091-3102.

(21) Wang, Z.; Yang, M.; Cheng, Y.; Liu, J.; Xiao, B.; Chen, S.; Huang, J.; Xie, Q.; Wu, G.; Wu, H. Dielectric properties and thermal conductivitly of epoxy composites using quantum-size silver decorated core/shell structured alumina/polydopamine. Composites, Part A 2019, 118, 302-311.

(22) Li, J.; Ma, J.; Chen, S.; He, J.; Huang, Y. Characterization of calcium alginate/deacetylatedkonjacglucomannan blend films prepared by $\mathrm{Ca}^{2+}$ crosslinking and deacetylation. Food Hydrocolloids 2018, 82, 363-369.

(23) Gandini, A. Polymers from Renewable Resources: A challenge for the future of macromolecular materials. Macromolecules 2008, 41 9491-9504.

(24) Gandini, A. Furans as offspring of sugars and polysaccharides and progenitors of a family of remarkable polymers: A review of recent progress. Polym. Chem. 2010, 1, 245-251.

(25) Anastas, P. T.; Warner, J. C.; Handbook of Green Chemistry Theory and Practice; Oxford University Press: New York, 1998.

(26) Calý, E.; Maffezzoli, A.; Mele, G.; Martina, F.; Mazzetto, S. E.; Tarzia, A.; Stifani, C. Synthesis of a novel cardanol-based benzoxazine monomer and environmentally sustainable production of polymers and bio-composites. Green Chem. 2007, 9, 754-759.

(27) Xu, H. L.; Lu, Z. J.; Zhang, G. Z. Synthesis and properties of thermosetting resin based on urushiol. RSC Adv. 2012, 2, 2768-2772.

(28) Thirukumaran, P.; Parveen, A. S.; Sarojadevi, M. Synthesis and copolymerization of fully biobased benzoxazines from renewable resources. ACS Sustainable Chem. Eng. 2014, 2, 2790-2801.

(29) Wang, C. F.; Sun, J. Q.; Liu, X. D.; Sudo, A.; Endo, T. Synthesis and copolymerization of fully bio-based benzoxazines from guaiacol, furfurylamine and stearylamine. Green Chem. 2012, 14, 2799-2806.

(30) Thirukumaran, P.; Shakila, A.; Muthusamy, S. Synthesis and characterization of novel bio-based benzoxazines from eugenol. RSC Adv. 2014, 4, 7959-7966.

(31) Kiskan, B.; Yagci, Y. Thermally curable benzoxazine monomer with a photodimerizable coumarin group. J. Polym. Sci., Part A: Polym. Chem. 2007, 45, 1670-1676.

(32) Froimowicz, P.; Arza, C. R.; Han, L.; Ishida, H. Smart, sustainable, and ecofriendly chemical design of fully bio-based thermally stable thermosets based on benzoxazine chemistry. ChemSusChem 2016, 9, 1921-1928.

(33) Dai, J.; Teng, N.; Peng, Y.; Liu, Y.; Gao, L.; Zhu, J.; Liu, X. Biobased benzoxazine derived from daidzein and furfurylamine: Microwave-assisted synthesis and thermal properties investigation. ChemSusChem 2018, 11, 3175-3183.

(34) Liu, X.; Zhang, R.; Li, T.; Zhu, P.; Zhuang, Q. Novel fully biobased benzoxazines from rosin: Synthesis and properties. ACS Sustainable Chem. Eng. 2017, 5, 10682-10692.

(35) Takaoka, M. The synthesis of resveratrol and its derivatives. Proc. Imp. Acad. 1940, 16, 405-407.

(36) Wehrli, C. Eur. Pat. 2468 706, 27 Jun 2012. 
(37) Subbaraju, G. V.; Mahesh, M.; Hindupur, H. R.; Suresh, T.; Ivanisevic, I.; Andres, M.; Stephens, K. U.S. Pat. Appl. 20110144212 A1, 16 Jun 2011.

(38) Fan, E.; Zhang, K.; Zhu, M.; Wang, Q. Obtaining resveratrol: from chemical synthesis to biotechnology production. Mini-Rev. Org. Chem. 2010, 7, 272-281.

(39) Shang, L.; Zhang, X.; Zhang, M.; Jin, L.; Liu, L.; Xiao, L. H.; Li, M.; Ao, Y. H. A highly active bio-based epoxy resin with multifunctional group: synthesis, characterization, curing and properties. $J$. Mater. Sci. 2018, 53, 5402-5417.

(40) Cash, J. J.; Davis, M. C.; Ford, M. D.; Groshens, T. J.; Guenthner, A. J.; Harvey, B. G.; Lamison, K. R.; Mabry, J. M.; Meylemans, H. A.; Reams, J. T.; Sahagun, C. M. High Tg thermosetting resins from resveratrol. Polym. Chem. 2013, 4, 38593865.

(41) Teong, S. P.; Yi, G.; Zhang, Y. Hydroxymethylfurfural production from bioresources: past, present and future. Green Chem. 2014, 16, 2015-2026.

(42) Agag, T.; Takeichi, T. Synthesis and characterization of novel benzoxazine monomers containing allyl groups and their high performance thermosets. Macromolecules 2003, 36, 6010-6017.

(43) Han, L.; Iguchi, D.; Gil, P.; Heyl, T. R.; Sedwick, V. M.; Arza, C. R.; Ohashi, S.; Lacks, D. J.; Ishida, H. Oxazine ring-related vibrational modes of benzoxazine monomers using fully aromatically substituted, deuterated, ${ }^{15} \mathrm{~N}$ isotope exchanged, and oxazine-ringsubstituted compounds and theoretical calculations. J. Phys. Chem. A 2017, 121, 6269-6282.

(44) Zhang, K.; Shang, Z.; Evans, C. J.; Han, L.; Ishida, H.; Yang, S. Benzoxazine atropisomers: Intrinsic atropisomerization mechanism and conversion to high performance thermosets. Macromolecules 2018, 51, 7574-7585.

(45) Dudek, J. A.; Kargol, J. A. Linear thermal expansion coefficients for an epoxy/glass matte-insulated solid cast transformer. Int. J. Thermophys. 1988, 9, 245-253.

(46) K, S. N.; Azechi, M.; Endo, T. Synthesis and properties of spirocentered benzoxazines. Macromolecules 2015, 48, 7466-7472.

(47) Ozawa, T. A new method of analyzing thermogravimetric data. Bull. Chem. Soc. Jpn. 1965, 38, 1881-1886.

(48) Flynn, J. H.; Wall, L. A. A quick, direct method for the determination of activation energy from thermogravimetric data. $J$. Polym. Sci., Part B: Polym. Lett. 1966, 4, 323-328.

(49) Lyon, R. E.; Safronava, N.; Quintiere, J. G.; Stoliarov, S. I.; Walters, R. N.; Crowley, S. Materials properties and fir test results. Fire Mater. 2014, 38, 264-278.

(50) Walters, R. N.; Lyon, R. E. Molar group contributions to polymer flammability. J. Appl. Polym. Sci. 2003, 87, 548-563. 